\title{
Research on promoting the conservation and utilization of agricultural water resources in in the Beijing-Tianjin-Hebei Region under the background of agricultural green development
}

\author{
Guang Zhao ${ }^{1}$, and Yanfen Dou ${ }^{1, *}$ \\ ${ }^{1}$ College of Economics and Management, Tianjin Agricultural University, 300384 Tianjin, China
}

\begin{abstract}
The conservation and utilization of agricultural water resources plays an important role in promoting the green transformation of agriculture. In this background, this paper systematically describes the current situation of agricultural water resources conservation and utilization in the Beijing-Tianjin-Hebei Region. At the same time, this paper points out that the agricultural water resource conservation and utilization in the Beijing-Tianjin-Hebei Region are confronted with such problems as the low degree of popularization and application of water-saving technology, the need to improve the depth and breadth of regional coordinated development, the unsound management mechanism, the insufficient capital investment and the imperfect talent support system. In view of the above problems, this paper puts forward countermeasures and suggestions to promote the conservation and utilization of agricultural water resources in the Beijing-Tianjin-Hebei Region, so as to better promote the agricultural green transformation and development in the Beijing-Tianjin-Hebei Region.
\end{abstract}

\section{Introduction}

Water is the core element of agricultural green development. Only by making efforts to achieve the coordinated development between agriculture and water resources can agricultural green transformation and development be further promoted. In September 2017, the general office of the CPC central committee and the general office of the state council issued Opinions on promoting green agricultural development through innovative systems and mechanisms, which formally put forward the concept of green agricultural development. Among them, more saving and efficient resource utilization is one of the main goals of green agriculture development, and resource use more efficient saving is an important task to improve the farmland irrigation water use coefficient, make the agricultural water use efficiency further ${ }^{[1]}$. With the development of social economy and agricultural production, in total water resources and utilization in Beijing-Tianjin-Hebei Region faces huge challenges, on the one hand is lack of water resources, on the other hand, utilization efficiency is not high. In order to make the Beijing-Tianjin-Hebei Region take the lead in the path of agricultural green development in China, it is necessary to explore effective ways to realize the conservation and utilization of agricultural water resources and escort the green transformation and development of regional agriculture.

\section{The current situation of agricultural water resources conservation and}

\section{utilization in the Beijing-Tianjin-Hebei Region}

\subsection{Water resources in the Beijing-Tianjin-Hebei Region}

The Beijing-Tianjin-Hebei Region is located in the north-central part of the north China plain, east of the Bohai Sea, north of Yanshan, west of Taihang Mountain, It has a temperate monsoon climate, with annual precipitation of about 400 to 800 millimetres, and less water resources. From the point of view of water resources per capita in the past ten years, the per capita water resources ownership in the Beijing-Tianjin-Hebei Region is generally decreasing, and the decline is large, In 2008, the water resources per capita in the BeijingTianjin-Hebei Region were 200.1 cubic meters per person. By 2017, the per capita water resources in the Beijing-Tianjin-Hebei Region had fall 90.2 cubic meters per person, down by $54.9 \%$ compared with 2008 . In addition, the surface water in the Beijing-Tianjin-Hebei Region also shows a downward trend in the past decade. In 2008, the surface water in the Beijing-Tianjin-Hebei Region was 8.807 billion cubic meters. In 2017, the surface water in the Beijing-Tianjin-Hebei Region totalled 8.255 billion cubic meters, which was $6.3 \%$ lower than that in 2008. On the whole, due to the impact of climate change, there is a serious imbalance of regional water resources in the Beijing-Tianjin-Hebei Region. On the whole, regional water resources in the

\footnotetext{
* Corresponding author: bbdd 2006@126.com
} 
Beijing-Tianjin-Hebei Region are seriously unbalanced due to the impact of climate change.

At the same time, compared with the national situation, the over-exploitation of groundwater in the Beijing-Tianjin-Hebei Region is serious, the water level drops obviously, and the development and utilization of groundwater is on the high side. Moreover, with the economic development, the acceleration of BeijingTianjin-Hebei integration and the adjustment of industrial structure, the utilization and development of groundwater will be further intensified. According to statistics, the groundwater in Beijing, Tianjin and Hebei has been on a downward trend in the past decade. In 2008, the total groundwater in Beijing, Tianjin and Hebei was 14.096 billion cubic meters. In 2017, the total groundwater in the Beijing-Tianjin-Hebei Region was 13.754 billion cubic meters, which was $2.4 \%$ lower than that in 2008. Among them, Beijing city was 1.66 billion cubic meters, Tianjin city was 460 million cubic meters, and Hebei province was 11.634 billion cubic meters. Due to the serious over-exploitation of groundwater, the subsidence area of the Beijing-Tianjin-Hebei reaches 90,000 square kilometres.

In addition, the water pollution situation is not optimistic, and the Beijing-Tianjin-Hebei Region belong to the Haihe River Basin in the Beijing-Tianjin-Hebei Region, Hebei province is located in the upstream, the Beijing-Tianjin multiple streams are integrated upstream and downstream, in the national top ten river, Haihe River Basin water system for severe pollution, inferior class $\mathrm{V}$ water proportion in the highest, according to the statistics by the end of 2018, The proportion of inferior class $\mathrm{V}$ water body in Tianjin is $25 \%$, the proportion of inferior class $\mathrm{V}$ water in Hebei province was $20.3 \%$. Meanwhile, over the past five years, the Beijing-TianjinHebei Region's wastewater discharge has increased by $3 \%$ to $5 \%$ year by year. In 2017, Beijing's sewage discharge was 1.87 billion cubic meters, Tianjin produced 910 million tons of sewage in 2017. At the same time, around $70 \%$ of the Beijing-Tianjin-Hebei Region's shallow groundwater pollution is increasing. In addition, there are about 130 black and smelly water bodies in the Beijing-Tianjin-Hebei Region, which are difficult to manage.

\subsection{The current situation of agricultural water resources conservation and utilization in the Beijing-Tianjin-Hebei Region}

\subsubsection{Agricultural water-saving irrigation area continues to increase}

Although China's agricultural irrigation system started late, but compared to other provinces and cities, BeijingTianjin-Hebei Region in water-saving irrigation has been at the forefront. In recent years, the area of water-saving irrigation in the Beijing-Tianjin-Hebei Region has been increasing year by year, saving water resources, improving the utilization efficiency of water resources and reducing the burden of farmers to a certain extent. As can be seen from the following table, the area of water-saving irrigation in the Beijing-Tianjin-Hebei Region increased from 3,409.5 thousand hectares in 2014 to $3,963.7$ thousand hectares in 2017, with an overall increase of $16.3 \%$. The largest increase was in Tianjin, which increased from 191.7 thousand hectares in 2014 to 235.5 thousand hectares in 2017, up $22.8 \%$. Hebei province also rose relatively large, it increased from 3,023.9 thousand hectares in 2014 to $3,527.5$ thousand hectares in 2017 , up $16.7 \%$.

Table 1. The statistical table of agricultural water-saving irrigation area in the Beijing-Tianjin-Hebei Region from 2014 to 2017

\begin{tabular}{|c|c|c|c|c|}
\hline Year & $\begin{array}{c}\text { The total area of the } \\
\text { Beijing-Tianjin-Hebei } \\
\text { Region (thousand } \\
\text { hectares) }\end{array}$ & Beijing & Tianjin & Hebei \\
\hline 2014 & 3409.5 & 193.9 & 191.7 & 3023.9 \\
\hline 2015 & 3544.8 & 197.2 & 207.6 & 3140 \\
\hline 2016 & 3736.7 & 195 & 227.5 & 3314.2 \\
\hline 2017 & 3963.7 & 200.7 & 235.5 & 3527.5 \\
\hline
\end{tabular}

\subsubsection{Agricultural water-saving irrigation technology matures}

The Beijing-Tianjin-Hebei Region has strengthened agricultural water-saving. Focusing on changing the way of irrigation water use and improving the utilization efficiency of irrigation water, the region has vigorously developed and popularized micro-irrigation and low pressure pipe to carry water transfer technologies to create a water-saving and efficient modern agriculture. According to figure 2 ,it can be seen by the end of 2017, the Beijing-Tianjin-Hebei Region are mainly composed of 1 low pressure pipe irrigation, low pressure pipe irrigation accounted for $73.9 \%$ of the whole area of water-saving irrigation area, and less of micro-irrigation and spray irrigation area, the total area of 3.8\% and 6.6\% respectively, while the other way of water-saving irrigation area accounted for $15.7 \%$ of total area, Beijing, for example, the Beijing municipal water saving irrigation area of 200.7 thousand hectares squared, the spray irrigation area of 31.85 thousand hectares, accounting for $15.9 \%$ of the total area, The area of micro-irrigation was 20.08 thousand hectares, accounting for $10 \%$ of the total area; the area of lowpressure pipe irrigation was 136.19 thousand hectares, accounting for $67.8 \%$ of the total area; the area of other ways was 12.6 thousand hectares, accounting for $6.3 \%$ of the total area. In addition, the Beijing-Tianjin-Hebei Region has realized irrigation piping, and through the installation of agricultural irrigation automation intelligent control cabinet device, agricultural irrigation water metering, to ensure the benign operation of the field project, to create conditions for efficient and watersaving irrigation construction. 


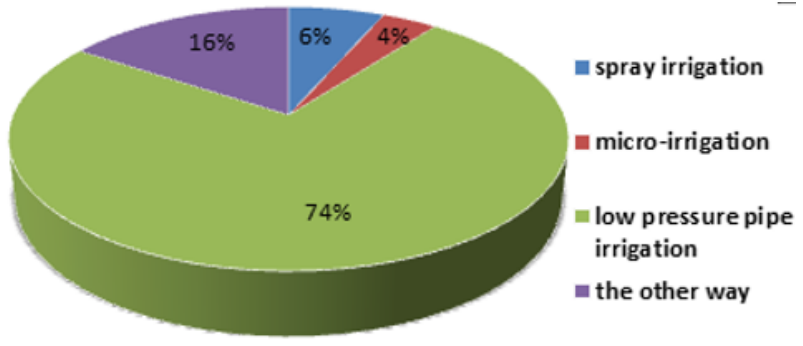

Fig. 1. The area comparison of different water-saving irrigation methods in the Beijing-Tianjin-Hebei Region in 2017

\subsubsection{Agricultural water price reform pilot to kick- start}

The Beijing-Tianjin-Hebei Region attaches great importance to the comprehensive reform of agricultural water prices, and takes the comprehensive reform of agricultural water prices as an important starting point for the conservation and utilization of agricultural water resources, achieving remarkable results. The BeijingTianjin-Hebei Region explored different types of water price reform mode. Beijing made clear to the irrigation water volume control in the 450 million Cubic meters in 2020 after the goal. According to the standards of 500 cubic meters, 200 cubic meters and 100 cubic meters per acre, the irrigation quota of facility agriculture, field and fruit trees was determined, water use targets will be reached in towns and villages, assigned to the home, the city's agricultural water within the quota pricing after an average of $0.25 \sim 1$ Yuan per cubic meters, and unified implementation of the over-quota surcharge system for water resources, grain crops and other crops are charged 0.08 Yuan per cubic meters and 0.16 Yuan per cubic meters respectively ${ }^{[2]}$. Tianjin is speeding up the construction of measurement facilities. For the well irrigation area and canal irrigation area, the smart control cabinet and vertical shaft metering pump station are respectively adopted to realize the single household metering by water volume. According to the principle of "total control and quota management", the agricultural water right is determined as 4230 cubic meters per hectare, a At the same time, a price management mechanism shall be established through consultation between the supplier and the seller, the approved operating cost of water is 0.24 Yuan per cubic meters, 0.21 Yuan per cubic meters is borne by individual users, the rest of the 0.03 Yuan per cubic meters by the finance of the zone. Hebei province carried out registration of the right to use water resources in accordance with the principle of "water everywhere, water distribution to households and water distribution by land". Hebei province has issued agricultural water certificates to 11.43 million water users, On the basis of the approved cost, three modes of water price reform are carried out, namely, "quota management and surcharge", " Receive according to quantity, return according to acre ", and "dosing and charging on time"[3]. By the end of 2017, the reform area of Hebei province has reached 806,700 hectares, and a total of 545 million Yuan has been allocated to finance subsidies for agricultural water price reform.

\section{The problems of saving and using agricultural water resources in the Beijing-Tianjin-Hebei Region}

\subsection{The extension system of agricultural water- saving irrigation technology is imperfect, the depth and breadth of the coordinated development of the three regions need to be improved}

Water-saving technology is the core element of green agricultural transformation, and it is also an indispensable condition for the conservation and utilization of agricultural water resources. In general, the Beijing-Tianjin-Hebei Region has been in a leading position in drip irrigation, micro-irrigation, "3S" technology and automatic control technology, but the agricultural water-saving irrigation technology popularization system still has problems such as low application degree and slow transformation of technical achievements. Reason is that many of the BeijingTianjin-Hebei Region at the grass-roots level technology popularization system "line is broken, net, people", water saving technology achievements transformation and promote efficiency is low, popularization system is not sound, failed to establish and popularization system that can meet the needs of the market, at the same time, the imperfect technology promotion agency, and marketing personnel's service quality level is low, single marketing channel, resulting in fine water saving irrigation, fertilization in the slow growth stage, it has affected the Beijing-Tianjin-Hebei Region the implementation of water saving irrigation engineering progress. In addition, the coordinated development of each region, each main body depth breadth is to ascend, Beijing-Tianjin-Hebei Region in water-saving technology exchange and mutual assistance were small, the advantages of various regions have not been fully utilized, and the main bodies such as scientific research institutes, agricultural colleges and universities and agricultural enterprises have only carried out some simple exchanges and cooperation, without deeper exchanges and collaborative development.

\subsection{Insufficient funds and imperfect support systems}

In the Beijing-Tianjin-Hebei Region, the saving and utilization of agricultural water resources is underfunded and the talent support system is not sound. At present, the Beijing-Tianjin-Hebei agricultural water-saving irrigation projects are mainly guided by national funds. The fiscal policies of districts and counties are matched, and the proportion of farmers' self-financing is relatively high, leading to a serious shortage of agricultural watersaving irrigation funds. Beijing-Tianjin-Hebei Region at the same time in the agricultural irrigation technology research and development and technology promotion 
funding shortfalls, lead to irrigation technology research and development is slow, unable to attract high-quality professional and technical personnel, and insufficient capital investment, to promote the government work efficiency is low, the reason is caused by a lack of funding, lead to can't recruit outstanding agricultural extension workers in the service of agricultural development, new media such as television, radio, also due to insufficient capital investment, lead to the efficiency of the agricultural technology popularization. In addition, there are still some problems in The BeijingTianjin-Hebei Region, such as the shortage of highquality scientific research personnel and agricultural technology extension personnel, which leads to the slow development of new technologies. In addition, some designers have insufficient understanding of agricultural water-saving irrigation projects and equipment, so the equipment they choose to use cannot meet the requirements of irrigation projects ${ }^{[4]}$.

\section{Summary and suggestions}

In the context of the shortage of agricultural water resources, serious water pollution and serious groundwater exploitation, the Beijing-Tianjin-Hebei Region has been committed to the conservation and utilization of agricultural water resources. But at the same time, it is faced with such problems as the low degree of popularization and application of water-saving technology, the need to improve the depth and breadth of regional coordinated development and the imperfect personnel and capital investment system. Therefore, the Beijing-Tianjin-Hebei Region must further promote the efficient, economical and utilization of agricultural water resources so as to promote the development of green agricultural transformation.

Based on this, this paper puts forward two suggestions for the existing problems in the conservation and utilization of agricultural water resources in the Beijing-Tianjin-Hebei Region: Firstly, we will strengthen coordination among major players and regions to tackle key problems and promote the application of water-saving agricultural irrigation technologies. Beijing-Tianjin-Hebei Region must strengthen the research and development of new technology, improve the agricultural colleges and universities, research institutes and enterprises innovation main body collaborative research mechanism, the higher agricultural colleges, such as China agricultural university, Chinese academy of agricultural sciences and other scientific research institutions and large and medium-sized agricultural enterprises together, form a reasonable to carry out the work of agricultural water-saving irrigation technology. At the same time, technical exchanges and assistance between Beijing, Tianjin and Hebei should be strengthened. Beijing and Tianjin have relatively developed scientific research capabilities and professional talents. Hebei province is a big agricultural province with a large area of farmland. Therefore, the three cities should make full use of their advantages and make coordinated efforts to tackle key problems, so as to promote the transformation and development of agriculture in the whole Beijing-TianjinHebei Region. In addition, the Beijing-Tianjin-Hebei Region should use information technology to manage water-saving irrigation projects, make full use of new media such as Internet and TV to publicize agricultural water-saving irrigation technology and timely report the achievements of water-saving irrigation projects, so as to accelerate the transformation and application of agricultural irrigation technology in the Beijing-TianjinHebei Region.

Thirdly, we will increase input in water-saving agricultural irrigation and strengthen the talent support system. Specific measures: (1) Agricultural water-saving irrigation projects should be based on government input. Therefore, government financial input should be increased, multi-channel and diversified investment mechanism for water-saving agriculture should be established, investment policies should be reformed, and special funds should be established. At the same time, we should raise funds from various sources, focus on the input of grain fields, and demonstrate and guide the cash crops. (2) The Beijing-Tianjin-Hebei Region should actively establish a talent support system, encourage more scientific research personnel and extension of science and technology personnel to participate in agricultural water-saving irrigation, give play to the role of agricultural colleges and universities in the BeijingTianjin-Hebei Region, train a large number of professional talents, and provide strong talent support for agricultural water-saving irrigation. At the same time, a group of grassroots agricultural technicians and new professional farmers with green development concepts and water-saving irrigation technologies should be trained, and new agricultural operators should be encouraged to take the lead in agricultural water-saving irrigation.

\section{Acknowledgement}

The research is a major social science project of Tianjin municipal commission of education "Research on the coordinated development of green agriculture in BeijingTianjin-Hebei".We are particularly grateful for it here. The number of the research is 2018JWZD17.

\section{References}

1. F. Yu, EE,hts on the realization of green agricultural transformation and development in China 4,42(2016)

2. BWA, Introduction to comprehensive reform of agricultural water price in Beijing 6,2(2018)

3. HWR, Hebei provincial water resources department supervises the comprehensive reform of agricultural water price in the province 10,10(2018)

4. C. Liu, W. Yang, J. Li. HHWC, Problems and countermeasures in the development and utilization of agricultural water resources in Tianjin 4,1(2018) 